\title{
INFLUENCE OF WORK-FAMILY CONFLICT AND FAMILY-WORK CONFLICT ON EMPLOYEES' TURNOVER INTENTIONS WITH GENDER, SOCIAL SUPPORT AND INDIVIDUAL VALUE AS MODERATING EFFECTS
}

\author{
Putu Irma Yunita \\ Gugup Kismono \\ Faculty of Economics and Business \\ Universitas Gadjah Mada \\ (gugup_kismono@ugm.ac.id)
}

\begin{abstract}
The purpose of this research is to examine the conflict between the work and family domains (work interfering with family-WIF and family interfering with work-FIW) and its influences on turnover intention. This research also examined the moderating effect of gender, social support and individual values on the relationship between the work-family conflict and turnover intentions. The participants of this study were 210 low and middle managers of four and five star hotels in Bali. This sample consisted of 126 males and 84 females. Multiple regression and hierarchical methods were used to test the proposed hypotheses. The result showed that WIF positively and significantly influences the turnover intention but FIW did not. It was also found that social support significantly moderates the relationships between variables studied, but gender and individual value had no impact on it.
\end{abstract}

Keywords: turnover intention, work interfering with family, family interfering with work, gender, social support, individual value.

\section{INTRODUCTION}

Employees resigning of their own free-will inflict a loss upon the company (Price \& Mueller, 1981). Losses incurred include: the recruitment and training costs, time and energy to organize another search/recruitment drive to fill the positions left by former employees (Hinkin \& Tracey, 2000; Amah, 2009; Davidson et al., 2010), the loss of the former employee's implicit knowledge and skill (Coff, 1997), and a possible decline in the organization's competitiveness within an industry (Lado \& Wilson, 1994; Dess \& Shaw, 2001).

One of the important variables that predicts the turnover intention is the conflict between work and family (Netemeyer et al.,2004). In the majority of adults, work and family are the two important things which should be well organized. These two domains have the same highlevel of involvement demand, and may result in an inter-role conflict. Foley et al. (2005) diffe- rentiated these conflicts into two forms dependent on the direction: job sourced conflict (workfamily conflict) and family sourced conflict (family-work conflict). A high-level of involvement demand at work may cause the person to have some difficulties in accomplishing his/her role in the family, because time and energy are naturally limited, and vice versa (Boyar et al., 2003).

Research about the work-family conflict rose in Western countries that had individualist cultures (Greenhaus \& Beutell, 1985). In these cultures, the family and job are two different things that are independent and are not related to one another (Hofstede et al., 2010). It means that if a person wants to increase his/her existence in a certain domain, then another domain must be sacrificed.

Different from the individualist Western countries, collectivist Eastern countries believe that the job and family are two things that are 
mutually supportive (Hofstede et al., 2010). In these cultures, work is rated as the family's welfare support (Wang et al., 2010). Cultural differences between Western and Eastern countries affect the perception of a conflict and the action to contend with it.

Research done by Spector et al. (2007) compared work-family conflict on employees' turnover intentions in two different cultures (individualist and collectivist). The result showed that work-family conflict had a positive and significant effect on employees' turnover intentions in both cultures. This finding is different from the concept of Hofstede et al. (2010): different cultures affect the perceived conflict.

The inconsistency between what Spector et al. (2007) found and Hofstede et al. (2010) produced in their concept, motivated the researcher to do another research related to the influence of the work-family conflict on employees' turnover intentions in collectivist cultures. In this research, the researcher enclosed a demographic variable (gender), a situational variable (social support), and an individual variable (individual value) as moderating variables. This was done because according to Eisenberger et al. (1990), the situational and individual variable could strengthen or weaken the conflict perception, which could be observed in the person's actions to cope with the conflict. Besides, the gender variable was also predicted to affect the conflict perception and action taken (resigning from a job) to overcome the conflict.

\section{LITERATURE REVIEW AND HYPOTHESIS}

Employees' turnover involves a series of processes, that is: the separation of the employment relationship with the former employee and the recruitment, training and placement of the new employee (McElroy et al., 2001). The whole process comes at a high cost (Davidson et al., 2010), which is why this process inflicts a financial loss on the company. But employees' turnover doesn't always have a negative effect. Dalton et al. (2010) found that dysfunctional employees' turnover would have a negative effect, but functional employees' turnover would have a positive effect. Dysfunctional employees' turnover occurs when a company has positive assessment on the employees, otherwise, employees who have(has) a negative assessment to the company and they have turnover intentions This condition has to be avoided by the company (Price \& Mueller, 1981) because the company will lose its potential resources. One way to predict voluntarily-employees' turnover is by measuring their turnover intention (Boyar et al., 2003; Barak et al., 2001). For that reason, an employees' turnover intention would be the dependent variable in this research.

Inter-role conflict is one of the predictors which affect an employees' turnover intention. Inter-role conflict happens when someone feel the pressures from different domains at the same time, when they are fulfilling their roles (Greenhaus \& Beutell, 1985). One form of interrole conflict is the work-family conflict (Cinamon \& Rich, 2002). This work-family conflict happens because of time-demands (time based conflict), pressure being felt (strain based conflict), and unsuitable behavior (behavior based conflict) (Greenhaus \& Beutell, 1985; Carlson et al., 2000). Consequences of this interrole conflict, for both the individual and company are increased stress at work, depression, decreasing job satisfaction, increasing withdrawal and turnover intention (Hammer et al., 2003; Judge \& Colquitt, 2004; Seto et al., 2004; Granday et al., 2005; Spector et al., 2007).

Foley et al. (2005) differentiated the workfamily conflict into two forms depending on the direction: job sourced conflict (work-family conflict, WFC) and family sourced conflict (familywork conflict, FWC). WFC occurs when personnel experience a high demand on their time, and pressures that occur because of the high work-demand and work load when doing their role in the work domain, so it will be difficult for them to fulfill their role in the family domain (Netemeyer et al.,1996). This condition may cause a negative condition for both the employees and the company. For employees the loss of time to fulfill their family roles because of their job, will create guilty feeling that may trigger stress, depression, anger, and declining 
physical health (Allen et al., 2000). To overcome this condition, their turnover intention may rise as a solution to the problem (Shaffer et al., 2001; Spector et al., 2007). Based on this, Hypothesis 1 is presented:

H1: Work-family conflict has a positive influence on an employees' intention turnover

Work-family conflict occurs when a high demand in the family domain causes a person some difficulties in doing his/her role in the job domain well (Netemeyer et al., 1996). It happens because a persons time and energy are naturally limited. For that reason, when they dedicate their time and energy to their role in the family domain, then their compliance in their work-role will not be optimal; for example, coming in late to work, a lack of concentration while doing their work, come to work exhausted or lacking sleep, and often taking leave or being missing from their job (Wang et al., 2004; Hammer et al., 2003). This results in employees receiving low performance assessments, causing them to feel ashamed and uncomfortable in their work. This condition is very likely to cause an employees' turnover intention to increase. Hypothesis 2 below was proposed based on this.

H2: Family-work conflict has a positive influence on an employees' turnover intention

The relationship between the work-family conflict and the family-work conflict might be different between men and women. This is because gender has a different social-meaning as shown by the roles done by men and women, in which they have different experiences and activities in their social lives (Wood \& Eagly, 2002). Putting in gender as a moderating variable in this research became an important argument, because according to Foley et al. (2005) a person's roles in the work and family domains were based on the expectation of their gender.

Men prioritize their time for their work, whereas women prioritize their time for the home and family. Therefore, men are used to getting pressure from the work domain and women become "invulnerable" to family-domain's pressures. For that reason, in accordance with the gender-role theory stated by Gutek et al. (1991), men and women have a different conflict sensitivity that is caused by pressures from their nonprioritized domain. It is also in line with Thompson and Walker (1989) that women are more sensitive to conflicts from the work domain (WFC), while men are more sensitive to conflicts from their family domain (FWC). This means that women will feel a conflict when pressure in their work domain makes it difficult to fulfill their family roles. Likewise with men, conflict will be felt when pressure from their family domain makes difficulties in their work domain.

In the context of Indonesia, which has a patriarchal culture, prevailing norms in society show that women are essentially responsible for housework, while men are responsible for making a living (Hastuti, 2011). These norms are also written into law: UU No.1 Year 1974 (content of article No.31). That is the reason why Indonesian women are predicted to have conflicts when work domain pressure makes it difficult for them to fulfill their family roles, whereas Indonesian men are presumed to have conflicts when family pressures make it difficult for them to fulfill their roles in the work domain. This condition caused the relationship between work-family conflict and family-work conflict, with a turnover intention, different between men and women. Based on this argument, hypothesis 3 and 4 are proposed below.

H3: Gender moderates positive influences of work-family conflict on an employees' turnover intention, and the influences are stronger among women.

H4: Gender moderates positive influences of family-work conflict on an employees' turnover intention, where the influences are stronger among men.

Another variable that might moderate the relationship between work-family conflict and family-work conflict with a turnover intention is social support. Social support is an interpersonal transaction involving emotional attention, instrumental assistance, and information or valuation (Carlson \& Perrewe, 1999). In accordance with 
the buffering perspective concept, social support might overcome a pressing situation in life caused by conflict, so it could reduce any negative impacts (Greenhaus \& Parasuraman, 1994 in Foley et al., 2005).

Associated with conflict in the work domain, social support from colleagues or supervisors was assessed to see if it could reduce the conflict felt that could then lower an employees' turnover intention (Kossek et al., 2011). This condition was explained in the social exchange theory stated by Blau (1964) in Allen et al. (2003) that is: when someone had received support from another person or organisation, then he/she would feel the need to return that kindness, for example with loyalty and commitment to the person/company (Eisenberger et al., 1990).

Associated with the work and family domain, social support can be differentiated into two forms, they are social support originated from the job (colleagues or supervisors) and social support that comes from the family (husband, parents/parents in law). This is based on Bellavia and Frone's (2005) consideration as written in Seiger and Weise (2009): when a person experiences conflict from a domain, the necessary social support should come from the direction of the conflict itself.

Social support in the workplace is needed when demand from the work domain is very high (Carlson \& Perrewe, 1999). Social support from the workplace can be given in the form of flexible working hours/times, colleagues' who are willing to share tasks and responsibilities, and supervisor's willingness to provide guidelines and moral support (Frye \& Breaugh, 2004; Foley et al., 2005). When a person experiences a high-pressure work domain that makes it difficult to fulfill his/her roles in the family domain (i.e. taking care of a sick son/daughter) that causes turnover intentions, social support from work supervisors (i.e. giving permission to go home early) can reduce the conflict felt. Thus, as stated in the social exchange theory, employees would feel the need to give back that understanding, for example with loyalty to the company. This opinion is also supported by the finding of Nissly et al. (2005) and Pienaar et al.
(2007). Based on this argument, hypothesis 5 was proposed below.

H5: Social support from the work domain moderates the positive influence of work-family conflict on employees' turnover intention. When the social support obtained from the work domain is high, the positive influence will be weak.

Family social support is usually given by the spouse (husband/wife) and parents/parents in law. Such social support is in the form of emotional and instrumental support (Kaufman \& Behrr, 1986 in Adams et al., 1996). When a person experiences a high demand in their family domain (i.e. taking care of children, doing housework), which requires a lot of time and energy, that will cause that person difficulties in their work domain. This condition can lead to the person getting poor/low performance assessments, which can make them feel uncomfortable and trigger a turnover intention. But, that may not happen if there is support from the spouse and/or parents/parents in law who could help with the running of the household, so that the resources crisis (time and energy) could be overcome. This opinion was supported by the finding of Greenhaus and Beutell (1985) and Seiger and Wiese (2009). According to these arguments, Hypothesis 6 was submitted as follow.

H6: Social support from the family moderates a positive influence on the work-family conflict on an employees' turnover intention. When the social support from the family domain gets stronger, the positive influence will be weakened.

Individual value is a motivation and of particular interest in that it affects human behavior (Seligman et al., 1996 in Struch et al., 2002; Savig \& Schwartz, 1995; Rokeach, 1973 in Schwartz et al., 2000). Everyone has their own priority values in their life, which affect their attitude and behavior. The high priority of a certain value is a determination that will steer them to see, accept, or avoid certain situations that aren't in line with this value (Schwartz et al., 2000). 
Associated with the inter-role theory (workfamily), when a person is more concerned with the value of their work (materialism), this would make that person more sensitive to conflicts caused by his/her involvement in the family domain. This means, his/her involvement in the family domain will create anxiety that this involvement will disrupt their job performance, and vice versa (Greenhaus et al., 2003). However, a priority on the value of family also has the potential to affect human behavior, because of the influence of the work-family conflict. Although work is an important matter in a person's life, when it takes a lot of time and resources, he/she may feel very anxious if the job negatively affects his/her family, which can then also negatively affect the job itself. For a person who is more concerned with the value of family, maintaining the integrity of the family is considered beneficial for his/her welfare. Research done by Masuda and Sortheix (2011) support this argument.

The value of the family would be included in this research, considering that the majority of Balinese (who were studied in this research) are more likely to have this value. Hence, hypotheses 7 and 8 are submitted.

H7: The individual value of the family moderates a positive influence on the workfamily conflict on an employees' turnover intention. When priority for the family is high, the positive influence will be strong.

H8: The individual value of the family moderates a positive influence on the familywork conflict on an employees' turnover intention. When priority for the family is high, the positive influence will be strong.

\section{RESEARCH METHOD}

\section{Research Context}

This research was done in Bali. This decision was based on various considerations. Firstly, the service industry, especially hospitality, in Bali is growing (Dinas Pariwisata Bali, 2009), thus it is facile for the researcher to get relevant samples. The hospitality industry was chosen because of the characteristics of the job. Working in the hospitality industry requires long and irregular working-hours and shifts (Blomme, 2010) that potentially cause the role-conflict that is rooted in the work domain.

Secondly, Bali is a province where the involvement of the people in the work domain is very high. This is shown by the percentage of people in work: $97.96 \%$ (BPS Bali, 2012). This fact also has the potential to cause conflict sourced from the work domain (WFC). Otherwise, the family domain is very likely to cause family sourced conflict (FWC) because Bali is a province where the involvement of the people in the family domain is very high; as shown by their cultural activities (i.e. mebanten and merainan). Besides that, their roles as parents demands a lot of their time and energy (Subiyanto, 2004; Sumatika, 2006). Thus, choosing Bali as our research's location was absolutely relevant within the context of this research.

\section{Participant and Data Collecting Procedure}

Respondents in this research were junior and middle managers in 4 and 5 star hotels. Employees who hold managerial positions in these hotels experience high-pressure, high work-load, and high time-demand working enviroments; which are suspected to be the source of stress and conflict; which is why the researcher chose these samples. The sampling technique was a purposive sampling with judgment: employees who had been working for at least a year, and were married with children.

Data was collected by a survey using questionnaires. The distribution and questionnaire collection were done by the researcher with the help of the human resource managers in the hotels. 250 questionnaires were sent out, 219 were completed, and 210 could be processed.

\section{Measurement}

Most of the variables in this research were measured with a 5 point Likert Scale $(1=$ very disagree, $5=$ absolutely agree), except for the gender variable. Work-family conflict (WFC) and family-work conflict (FWC) were measured by asking 9 question-items each, this measure- 
ment was developed by Carlson et al. (2000). The alpha value for the WFC and FWC variables were 0.879 and 0.848 , both variables showed reliability. An example of a WFC's questionitem is: my job limits me in doing my family activities. An example of a FWC's question-item is: because of the high-demand from domestic matters, I often feel indecisive while I work in the hotel because of my household matters.

Employees' turnover intention was measured with 4 question-items which were developed by Mobley et al. (1978) and adopted by Kismono (2011). The alpha value for this variable was 0.651 , shown again as being reliable. A question-item example: I intend to leave my job in 12 years time.

The social support variable was measured with 23 question-items, 15 question-items intended for the social support from the work domain were developed by Parasuraman et al. (1992) and Lambert (2000) (an example: my colleagues are willing to help me to do my job), and the remaining 8 question-items intended for the social support from the family domain were developed by Haus and Kahn (1985) (for example: my husband/wife is willing to listen to me talk about the problems I face). The alpha values for the social support from the work domain and family domain variables were 0.900 and 0.862 respectively, both shown as reliable.

The family-individual value was measured with 8 question-items which were developed by Lindeman and Verkasalo (1984) and adopted by Masuda and Sortheix (2011). The alpha value for this variable was 0.913 , again shown as being reliable. A question-example for the individual value: spending time with my family at home is the most important thing in my life.

The validity test was done using a Confirmatory Factor Analyses (CFA). The questionitem used for the further analysis in this research were items with a factor loading $\geq 0,40$. This was based on the opinion of Hair et al. (2010): with a total of 210 samples, then the value of the factor loadings is $\geq 0,40$.

\section{Model}

The relationship model between variables that hypothesized was summarized in Figure 1. Hypothesis testing in this research was carried out using a Multiple Regression Analysis and Hierarchical Regression Analysis with the SPSS version 15.0 for Windows.

\section{RESULTS AND DISCUSSION}

\section{Descriptive Statistic}

Table 1 showed the descriptive statistic consists of the mean, standard deviation, and coefficient correlation between the variables. According to the mean value, it could be explained that respondents to this research felt high levels of social support from both their work and family domains, and also own a high family-individual value. Furthermore, both the work-family conflict and family-work conflict, and also the turnover intention felt by the respondents was relatively low.

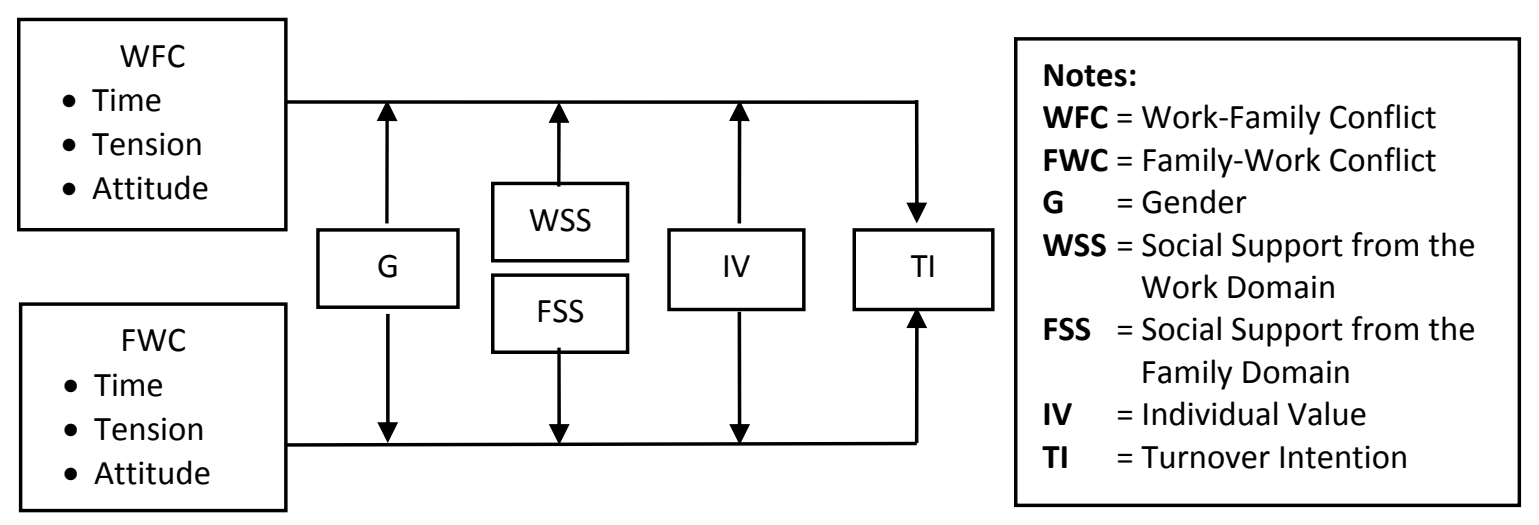

Figure1. Research Framework 
Table 1. Means, standard deviation, and coefficient correlation between variables

\begin{tabular}{|c|c|c|c|c|c|c|c|c|c|c|}
\hline \multirow{2}{*}{ No } & \multirow{2}{*}{ Variable } & \multirow{2}{*}{ Mean } & \multirow{2}{*}{$\begin{array}{c}\text { Standard } \\
\text { Deviation }\end{array}$} & \multicolumn{7}{|c|}{ Correlation } \\
\hline & & & & 1 & 2 & 3 & 4 & 5 & 6 & 7 \\
\hline 1 & Work-Family Conflict & 2.294 & 0.688 & 1 & & & & & & \\
\hline 2 & Family-Work Conflict & 2.137 & 0.569 & $0.810^{* *}$ & 1 & & & & & \\
\hline 3 & Social Support from Work & 3.966 & 0.456 & $-0.164 *$ & $-0.265 * *$ & 1 & & & & \\
\hline 4 & Social Support from Family & 4.186 & 0.539 & $-0.185 * *$ & $-0.189 * *$ & $0.512 * *$ & 1 & & & \\
\hline 5 & Family Individual Value & 4.556 & 0.490 & -0.071 & $-0.127^{*}$ & $0.352 * *$ & $0.592 * *$ & 1 & & \\
\hline 6 & Gender & 0.600 & 0.491 & 0.045 & 0.087 & 0.040 & -0.071 & -0.066 & 1 & \\
\hline 7 & Turnover Intention & 2.568 & 0.783 & $0.363 * *$ & $0.349 * *$ & $-0.153 *$ & -0.072 & -0.024 & 0.052 & 1 \\
\hline
\end{tabular}

Notes: ** significant on $0.01, *$ significant on 0.05

According to the value of the coefficient correlation between the variables, it could be explained that both conflicts in this research correlated significantly $(\mathrm{r}=0,810, p<0,01)$. Both conflicts correlated negatively with social support from work and family, and correlated positively with employees' turnover intention. Only the family-work conflict correlated negatively with the family-individual value; the work-family conflict also correlated negatively with the family-individual value, but it is statistically not significant. Furthermore, both the work-family conflict and family-work conflict correlated positively with gender but the correlations also are not significant.

\section{Hypothesis Test}

Table 2 showed the result of the hierarchyregression analysis of the influence of the WFC and FWC on turnover intention, with gender as a moderating variable. In the first step of the test it can be seen that the WFC influenced positively and significantly on employees' turnover intentions $(\beta=0,233, \mathrm{p}<0,05)$. Thus, H1 (Hypothesis $1)$ is supported. The FWC also influenced positively $(\beta=0,161)$ on employees' turnover intentions, but it is not statistically significant $(p>0,10$ ). With that result, H2 (Hypothesis 2) is not supported.

Step 1 and 2 shown in Table 2, were done to test the influence of gender as a moderating variable on the relationship between the WFC and FWC on turnover intention. The influence of this moderating variable was tested using interaction inter-variables. For example, the influence of gender moderation on the relationship of the WFC with turnover intention was tested using interaction between the WFC and gender. If

Table 2. Hierarchical-regression analysis of the influence of WFC and FWC on turnover intention with gender as moderating variable

\begin{tabular}{|c|c|c|c|c|}
\hline & Variable & Model 1 & Model 2 & Model 3 \\
\hline \multicolumn{5}{|c|}{ Step 1: Independent } \\
\hline & Work-Family Conflict & $0,233^{*}$ & $0,235^{*}$ & 0,176 \\
\hline & Family-Work Conflict & 0,161 & 0,157 & $0,345^{*}$ \\
\hline \multicolumn{5}{|c|}{ Step 2: Moderator } \\
\hline & Gender & & 0,028 & 0,417 \\
\hline \multicolumn{5}{|c|}{ Step 3: Interaction } \\
\hline & Interaction Work-Family Conflict with Gender & & & 0,244 \\
\hline & Interaction Family-Work Conflict with Gender & & & $-0,677$ \\
\hline Adjusted R2 & & 0,132 & 0,129 & 0,134 \\
\hline$\Delta \mathrm{R}^{2}$ & & 0,141 & 0,001 & 0,013 \\
\hline$\Delta \mathrm{F}$ & & 16,924 & 0,186 & 1,575 \\
\hline
\end{tabular}

Notes: $\mathrm{n}=210 ; \quad+\mathrm{p}<0,10 ; \quad * \mathrm{p}<0,05 ; * * \mathrm{p}<0,01$ 
the interaction is statistically significant (as shown in Model 3), the influence of the moderation would also be significant. Table 2 showed that interaction between the WFC and gender ( $\beta$ $=0,244 \mathrm{p}>0,10)$ is not significant, so $\mathrm{H} 3$ is not supported. Interaction of the FWC with gender $(\beta=0,677 p>0,10)$ is also not significant. Thus, $\mathrm{H} 4$ is also not supported. This result showed that the gender moderation influence is not statistically significant, both in the relationship between the WFC and turnover intention, and the FWC and turnover intention.

Table 3 showed the result of the regression analysis of the WFC on employees' turnover intentions with social support from the work domain as a moderating variable. The result showed that social support from the work domain moderated those influences $(\beta=-1,111 p<$ 0,10 ), this means H5 is supported (significance level 0.1). A negative sign on the $\beta$ showed that the greater the social support obtained from the work domain, the influence of the WFC on turnover intention would be weakened.

Table 4 showed that the social support from the family domain significantly moderated the influence of the FWC on turnover intention $(\beta=$ $-0,804 \mathrm{p}<0,10$ ), which means H6 is supported. The negative sign on the $\beta$ showed that the more social support given by the family domain, the weaker the influence of the FWC on turnover intention would be.

Table 3. Hierarchical-regression analysis of the influence of WFC on turnover intention with social support from work domain as moderating variable

\begin{tabular}{lrrr}
\hline \multicolumn{1}{c}{ Variable } & Model 1 & Model 2 & Model 3 \\
\hline $\begin{array}{l}\text { Step 1 : Independent } \\
\quad \text { Work-Family Conflict }\end{array}$ & $0,233^{*}$ & $0,244^{*}$ & $1,316^{*}$ \\
$\quad \begin{array}{l}\text { Step 2: Moderator } \\
\quad \text { Social Support from the Work Domain }\end{array}$ & & $-0,070$ & 0,319 \\
Step 3: Interaction & & & $-1,111^{+}$ \\
$\quad$ Interaction Work-Family Conflict & & & \\
$\quad$ With Social Support from the Work Domain & 0,132 & 0,134 & 0,145 \\
\hline Adjusted $\mathrm{R}^{2}$ & 0,141 & 0,006 & 0,015 \\
$\Delta \mathrm{R}^{2}$ & 16,924 & 1,373 & 3,710 \\
\hline $\mathrm{F}$ & & &
\end{tabular}

Notes: $\mathrm{n}=210 ;+\mathrm{p}<0,10 ; * \mathrm{p}<0,05 ; * * \mathrm{p}<0,01$

Table 4. Hierarchical-regression analysis of the influence of FWC on turnover intention with social support from family domain as moderating variable

\begin{tabular}{lrcc}
\hline \multicolumn{1}{c}{ Variable } & Model 1 & Model 2 & Model 3 \\
\hline $\begin{array}{l}\text { Step 1 : Independent } \\
\quad \text { Family Work Conflict }\end{array}$ & 0,161 & 0,161 & $0,937^{*}$ \\
$\quad \begin{array}{l}\text { Step 2: Moderator } \\
\quad \text { Social Support from the Family }\end{array}$ & & 0,001 & $0,344^{+}$ \\
Step 3: Interaction & & & $-0,804^{+}$ \\
$\quad$ Interaction Family-Work Conflict & & & \\
$\quad$ With Social Support from the Family & 0,132 & 0,128 & 0,138 \\
\hline Adjusted $\mathrm{R}^{2}$ & 0,141 & 0,000 & 0,014 \\
$\Delta \mathrm{R}^{2}$ & 16,924 & 0,000 & 3,391 \\
$\Delta \mathrm{F}$
\end{tabular}

Notes: $\mathrm{n}=210 ; \quad+\mathrm{p}<0,10 ; \quad * \mathrm{p}<0,05 ; \quad * * \mathrm{p}<0,01$ 
Table 5 showed the test result of the familyindividual value as a moderating variable on the influence of the WFC and FWC on turnover intention. The result showed that the family individual value is significant as a moderating variable on the influence of the WFC on turnover intention, but in a reverse direction $(\beta=$ $-1,982 \mathrm{p}<0,10)$. This finding showed that the family-individual value moderated the influence of the WFC on turnover intention. The higher a person's priority for his/her family, the turnover intention caused by a WFC would be weaker. That's why H7 (Hypothesis 8) is partially supported. Regarding Hypothesis 8, results showed that the moderating effect of the individual value on the influence of the FWC on turnover intention is statistically not significant $(\beta=0,875 \mathrm{p}>$ $0,10)$. Consequently, H8 is not supported.

\section{Discussion}

Hypothesis 1 in this research: "the WFC has a positive influence on employees' turnover intention", is supported. This finding is in accordance with Spector et al. (2007). In this research context, employees who held managerial positions in 4 and 5 stars hotels, are perceived to have a reasonably high role-demand in the work domain. This condition happens because as someone's posisition at work gets higher, their duties and responsibilities also become more serious (Karatepe \& Badar, 2006). On the other hand, the role-demand on the person in the family domain is also perceived to be high; i.e. their role as a parent, as a housekeeper, and their role in their social life. When a person cannot perform their role in the family well, then they will feel guilty for the family (Seto et al., 2004). To overcome that guilty feeling, their turnover intention and desire to find a new job will be more intense.

The work-family conflict is not significant in influencing employees' turnover intention: $\mathrm{H} 2$ was not supported. This finding is in accordance with the argument put forward by Hofstede et al. (2010): people in a collectivist culture considered work and family as a two-related domain.

Generally, a family's welfare depends on a decent income, which requires a good, reasonably high salary/stress job. So, when an Indonesian who is experiencing a family-work conflict, does not directly quit their job, it is because they would then lose the income that is used to maintain the welfare of the family. Losing this income will trigger new conflicts in their life. The samples in this research are hotel managers who have good a position and income, which does make them think twice about leaving their current job.

Table 5. Hierarchical-regression analysis of the influence of WFC and FWC on turnover intention with the family-individual value as a moderating variable

\begin{tabular}{lrrr}
\hline \multicolumn{1}{c}{ Variable } & Model 1 & Model 2 & Model 3 \\
\hline Step 1 : Independent & & & \\
$\quad$ Work-Family Conflict & $0,233^{*}$ & $0,231^{*}$ & $2,125^{+}$ \\
$\quad$ Family-Work Conflict & 0,161 & 0,164 & $-0,670$ \\
Step 2: Moderator & & & \\
$\quad$ Family Individual Value & & 0,014 & $0,327^{+}$ \\
Step 3: Interaction & & & \\
$\quad$ Interaction Work-Family Conflict & & & $-1,982^{+}$ \\
$\quad$ With the Family Individual Value & & & \\
$\quad$ Interaction Family-Work Conflict & & & 0,875 \\
$\quad$ With the Family Individual Value & & & \\
\hline Adjusted $\mathrm{R}^{2}$ & 0,132 & 0,128 & 0,138 \\
$\Delta \mathrm{R}^{2}$ & 0,141 & 0,000 & 0,018 \\
$\Delta \mathrm{F}$ & 16,924 & 0,043 & 2,148 \\
\hline Notes: $\mathrm{n}=210 ;+\mathrm{p}<0.10 ; * \mathrm{p}<0.05 ; * * \mathrm{p}<0.01$ & & &
\end{tabular}


Gender insignificantly moderated the influence of the WFC and FWC on employees' turnover intentions: $\mathrm{H} 3$ and $\mathrm{H} 4$ are not supported. This finding might be because men do not feel the WFC and women are not feeling the FWC, both of which could push their turnover intention. Hidayati (2005) in Kismono (2011) explained that nowadays men are willing to share the housework with their wives. As a mind-shift of modern men, this is now seen in Bali too. For some men, work is not the only important domain in their life, their family domain has also become a priority.

On the other hand, women are also having modern thoughts associated with their roles in the work and family domains. Cinamon and Rich (2002) said that there has been a significant role-shifting between men and women in the work and family domains. Women are now more involved in work and business, often holding high positions. This means, women are not only prioritizing their role in the family, but their job is also important to them (Daily et al., 1999). This phenomenon is also seen in Bali.

Some researchers argued that there had been a balance of commitments between men and women in their roles in their work and family domains (Novack \& Novack, 1996; Willinger, 1993 in Cinamon \& Rich 2002). Balancedcommitments now mean that both men and women do not differ significantly in experiencing the conflicts that cause their turnover intentions. Because of that reason, gender, in this research, does not moderate the WFC and FWC on turnover intention.

Social support from the job significantly moderated the influence of the WFC on employees' turnover intentions. The greater the social support obtained, the weaker the influence became. This finding supports $\mathrm{H} 6$ and also is in line with the research of Nissly et al. (2005).

The hospitality industry, which is loaded with work-demands and pressures, produces high-stress employees. Long working hours leave little time to carry out their roles in the family domain. Their work-tension also leaves them physically exhausted. Therefore, any social support from their work domain is felt as a posi- tive working condition by the employees, and can help to reduce the negative effects of workdemands and pressures (Karasek \& Theorel, 1990 in Kim \& Stoner, 2008). Social support in the work domain comes from colleagues and supervisors (Lewin \& Sager, 2008). This support is valued in helping them to overcome the stress. Besides, employees will also feel a part of the company-family (Dollard et al., 2000). As a result, as stated in the social exchange theory, these employees will respond with loyalty to the company, which means their turnover intention will be low.

Social support from the family significantly moderated the influence of the FWC on employees' turnover intentions. This finding supports $\mathrm{H} 6$ which is also in line with the buffering effect concept by Greenhaus and Parasuraman (1994 in Foley et al., 2005). Social support from the family is a solution to overcome the demands and tensions caused by conflicts sourced from the family: the parental role, housekeeping role, and social activities.

In the Balinese context, having parents/ parents-in-law available means a lot for working men/women, as they take over the mebanten and making banten tasks (both are examples of social activities related to the religion and culture in Bali). With that help, a lack of time problem can be overcome. As the result, role fulfillment in the work domain can be obtained. A person who gets social support from the family may be able to manage physical exhaustion, so that they can concentrate on their job. Then, they will not report to work late, and any uncomfortable feelings towards their colleagues or supervisors, which can trigger a turnover intention, can be overcome.

The family individual value moderated the influence of the WFC, but with a negative direction: $\mathrm{H} 7$ is partially supported. It means, the more a person prioritized the family, the weaker would be the turnover intention. This finding can be explained with the concept of Hofstede et al. (2010): work and family are two domains that support each other. That is why, for a person to support the welfare of their family; he/she needs to maintain a good economic condition (ie a well 
paid job) (Yang et al., 2000). So, for those who have a family individual value, they see a WFC as a positive signal, that they have a well paid job and good career, so it will not trigger the turnover intention.

In collectivist cultures (one of them is Bali), a job is valued as an important issue because most activities in the family need financial support, for example: tuition fees for children, insurance, household expenses (including a series of ceremonial activities, from baby showers until the marriage of the children, which are the parent's responsibility in Balinese culture), and social expenses. All of those expenses must be guaranteed by married couples. To meet those needs, an established, secure, constant source of income is a must. That is the reason why the higher a person places their value for the family (love his/her family), the higher endurance level the person has; in spite any work-family conflicts they may face.

The discussion above is also connected to $\mathrm{H} 8$, which is not supported. A person, who has a high family individual value, will make every effort to make the family prosperous through hard work and a strong-commitment to the job. As a result, every aspect that potentially interrupts their career will be carefully managed. In this context, the FWC is also optimally managed so as not to interrupt the job and wouldn't trigger a turnover intention. Statistically, because the FWC is not statistically significant in influencing a turnover intention, the moderation effect of the individual value on the relationship between these variables is also not significant.

\section{CONCLUSIONS, LIMITATIONS, AND SUGGESTIONS FOR THE NEXT RESEARCH}

This research's findings showed that the work-family conflict influenced employees' turnover intention. Social support, both from the work and family domains, moderate the influence of a role-conflict (work and family) on employees' turnover intentions. These findings are valid for 4 and 5 star hotel managers in this research. Those managers were easily prone to work-family conflicts, because of the high pres- sure and high time-demand characteristics of jobs in the hospitality industry.

This finding also supports the social exchange theory and buffering perspective; when a person obtains help from others (be it emotional, instrumental, or informational help), it can lighten the problems faced by that person; then negative behavior can be avoided. Furthermore, positive support from the employing company will get a positive response from the employees. For that reason, the company needs to give social support to their employees. Some forms of social support in the hospitality industry are sufficient break-times, a supervisor's willingness to discuss job and family-related problems, and forming a solid working team.

The company can also motivate every family to give support for the working family member. One of the methods is involving the employees' families in various programs that are organized by the company. In this way, family members will understand the working conditions of their spouse/child/son-or-daughter-in-law. This empathic feeling will increase family-social support, which will create a positive effect, because it will become a buffer for the negative effects of the inter-role conflict.

This research only explains about the source of any social support given (from the work and family domains), in the context of a role-conflict in the work and family domains. There are many different forms of social support. Each of them might have a different influence on the relationship between job and family on the turnover intention. For future research, it is suggested to explore each form of social support separately (emotional, instrumental, and informational support). The aim is to capture the behavior in each variable, so that organizational policies can be formulated more precisely.

Participants in this research wereare 4 and 5 stars hotel managers, in the context of the Balinese culture. Although the influence of the sample's context and characteristics on various research variables were not specifically explained, probably the samples' context and characteristics did influence the research findings. Therefore, 
any generalization based on this finding should be carefully constructed.

Data in this research were collected from self-report questionnaires. Common method bias is very likely to happen. Besides, cross-sectional research design is not able to explain the cause and effect of the variables examined. Longitudinal design will be more suitable if the aim of the research is to identify the causes and effects.

\section{REFERENCES}

Adams, G. A., L. A. King and D. W. King, 1996. "Relationships of job and family involvement, family social support, and workfamily conflict with job and life satisfaction". Journal of Applied Psychology, 81 (4), 411-420.

Allen, D. G., L. M. Shore and R. W. Griffeth, 2003. "The role of perceived organizational support and supportive human relation practices in the turnover process". Journal of Management, 29, 99-118.

Allen, T. D., D. L. Herst, C. S. Bruck and M. Sutton, 2000. "Consequences associated with work-to-family conflict: A review and agenda for future research". Journal of Occupational Health Psychology, 5, 94-107.

Amah, O. E., 2009. "Job satisfaction and turnover intention relationship: the moderating effect of job role centrality and life satisfaction". Research and Practice in Human Resource Management, 17, 24-35.

Barak, M. M., J. A. Nissly and A. Levin, 2001. "Antecedents to retention and turnover among child welfare, social work, and other human service employee: what can we learn from past research? a review and metaanalysis". Social Service Review, 75, 625661.

Blomme, R. J., A. V. Rheede and D. M. Tromp, 2010. "Work-family conflict as a cause for turnover intentions in the hospitality industry". Tourism and Hospitality Research, 10, 269-285.

Boyar, S. L., C. P. Maertz, A. W. Pearson and S. Keough, 2003. "Work-family conflict: a model of linkages between work and family domain variables and turnover intentions". Journal of Managerial Issues, 15, 175-190.
Badan Pusat Statistik Ketenagakerjaan (BPS) Bali. Available at bali.bps.go.id/brs/nasker/ bsr_nasker_11_2012.pdf.

Carlson, D. S. and P. L. Perrewe, 1999. "The role of social support in the stressor-strain relationship: an examination of work-family conflict". Journal of Management, 25, 513540.

Carlson, D. S., K. M. Kacmar and L. J. Williams, 2000. "Construction and initial validation of a multidimensional measure of work-family conflict". Journal of Vocational Behaviour, 56, 249-276.

Cinamon, R. G. and Y. Rich, 2002. "Gender differences in the importance of work and family roles: Implication for work-family conflict". Sex Role, 47(11), 531-541.

Coff, R. W., 1997. "Human assets and management dilemmas: coping with hazards on the road to resource-based theory". Academy of Management Review, 22, 374-402.

Daily, C. M., S. T. Certo and D. R. Dalton, 1999. "A decade of corporate women: Some progress in boardroom, none in the executive suite". Strategic Management Journal, 20, 93-99.

Davidson, M. G., N. Timo and Y. Wang, 2010. "How much does labour turnover cost? a case study of Australian four- and five- star hotels". International Journal of Contemporary Hospitality Management, 22, 451-466.

Dess, G. G. and J. D. Shaw, 2001. "Voluntary turnover, social capital and organizational performance". Academy of Management Review, 26, 446-456.

Dollard, M. F., H. R. Winefield, A. M. Winefield and J. De Jonge, 2000. "Psychological job strain and productivity in human service worker: A test of the demand-control-support model". Journal of Occupational and Organizational Psychology, 73 (4), 501-510.

Eisenberger, R., P. Fasolo and V. DavisLaMastro, 1990. "Perceived organizational support and employee diligence, commitment and innovation". Journal of Applied Psychology, 75, 51-59.

Foley, S., H. Y. Goe and S. Lui, 2005. "The effect of work stressor, perceived organizational support, and gender on work-family conflict in Hongkong". Asia Pacific Journal of Management, 22, 237-256. 
Frye, N. K. and J. A. Breaugh, 2004. "Familyfriendly policies, supervisor support, workfamily conflict, family-work conflict, and satisfaction: a test of conceptual model". Journal of Business and Psychology, 19, 197-220.

Granday, A. A., B. L. Cordeiro and A. C. Crouter, 2005. "A longitudinal and multi-source test of the work-family conflict and job satisfaction relationship". Journal of Occupational Psychology, 78, 1-20.

Greenhaus, J. H. and N. J. Beutell, 1985. "Sources of conflict between work and family roles". The Academy of Management Review, 10, 76-88.

Greenhaus, J. H., K. M. Collins and J. D. Shaw, 2003. "The relationship between workfamily balance and quality of life". Journal of Vocational Behaviour, 63, 510-531.

Gutek, B. A., S. Searle and L. Klepa, 1991. "Rational versus gender role explanation for work-family conflict". Journal of Applied Psychology, 76, 560-568.

Hair, J. F., W. C. Black, B. J. Babin and R. E. Anderson, 2010. Multivariate Data Analysis: A Global Perspective. New York: Pearson.

Hammer, L. B., T. N. Bauer and A. A. Granday, 2003. "Work-family conflict and work related withdrawal behavior". Journal of Business and Psychology, 17, 419-436.

Hastuti, E. L., 2011. Hambatan sosial budaya dalam pengarusutamaan gender di Indonesia. Available at http://ratikautama.blog. fisip.uns.ac.id/files/2011/12/8-soca-endanghambatan-sosbud.pdf.

Hinkin, T. and B. Tracey, 2000. "The cost of turnover". Cornel Hotels and Restaurant Administration Quarterly, 14, 14-20.

Hofstede, G., G. J. Hofstede and M. Minkov, 2010. Cultures and Organization: Software Of The Mind: Intercultural Cooperation and Its Importance for Survival. New York: Mc Graw Hill.

Iqbal, A., 2010. "Employee turnover: causes, consequences and retention strategies in the Saudi organizations". The Business Review, Cambridge, 16, 257-265.

Judge, T. A. and J. A. Colquitt, 2004. "Organizational justice and stress: the mediating role of work-family conflict". Journal of Applied Psychology, 89, 359-404.

Karatepe, O.M. and I. Baddar, 2006. "An empirical study of the selected consequences of frontline employees work-family conflict and family-work conflict". Tourism Management, 27, 1017-1028.

Kim, H. and M. Stoner, 2008. "Burnout and turnover intention among social workers: Effects of role stress, job autonomy and social support". Administration in Social Work, 32 (3), 5-25.

Kismono, G., 2011. "The Relationship Between Job Embeddedness, Work-Family Conflict and The Impact of Gender on Turnover Intention: Evidence from the Indonesian Banking Industry". Unpublished Dissertation. Perth: Curtin University.

Kossek, E. E., S. Pichler, T. Bodner and L. B. Hammer, 2011. "Workplace social support and work-family conflict: a meta-analysis clarifying the influence of general and work-family-specific supervisor and organizational support". Personnel Psychology, 64, 289-313.

Lado, A. A. and M. C. Wilson, 1994. "Human resource systems and competitive advantage: a competency-based perspective". Academy of Management Review, 18, 699727.

Lewin, J. E. and J. K. Sager, 2008. "Salesperson burnout: A test of the coping-mediational model of social support". Journal of Personal Selling and Sales Management, 28, 233-246.

Masuda, A. D. and F. M. Sortheix, 2011. "Workfamily value, priority goals and life satisfaction: a seven year follow-up of MBA students". Journal Happiness Study, 13 (6), 1131-1144.

McElroy, J. C., P. C. Morrow and S. N. Rude, 2001. "Turnover and organizational performance: a comparative analysis of the effect voluntary, involuntary, and reduction-inforce turnover". Journal of Applied Psychology, 86, 1294-1299.

Mobley, W. H., 1982. "Some unanswered question in turnover and withdrawal research". Academy of Management, 7, 111-116.

Netemayer, R. G., J. S. Boles and R. McMurrian, R., 1996. "Development and 
validation of work-family conflict and family-work conflict scales". Journal of Applied Psychology, 81, 400-410.

Netemayer, R. G., T. Brashear-Alejandro and J. S. Boles, 2004. "A cross-national model of job relatedoutcome of work-role and family role variables: A retail sales context". Journal of the Academy of Marketing Science, $32,49-60$.

Nissly, J. A., M. E. Mor Barak, M. E. and A. Levin, 2005. "Stress, social support, and workers intentions to leave their jobs in public child welfare". Administration in Social Work, 29 (1), 79-100.

Novack, L.L. and Novack, 1996. "Being female in the eighties and nineties: Conflicts between new opportunities and traditional expectations among white, middle class, heterosexual college women". Sex Roles, $35,57-77$.

Pienaar, J., C. F. Sieberhagen and K. Mostert, 2007. "Investigating turnover intentions by role overload, job satisfaction and social support moderation". SA Journal of Industrial Psychology, 33 (2), 62-67.

Price, J. L. and C. W. Mueller, 1981. "A causal model of turnover for nurses". The Academy of Management Journal, 24, 543-565.

Savig, L. and S. H. Schwartz, 1995. "Value priorities and readiness for out-group social contact". Journal of Personality and Social Psychology, 69, 437-448.

Schwartz, S. H., L. Sagiv and K. Boehnke, 2000. "Worries and values". Journal of Personality, 68, 309-346.

Seiger, C. P. and B. S. Wiese, 2009. "Social support from work and family domains as an antecedent or moderator of work-family conflict?" Journal of Vocational Behavior, 75, 26-37.

Seto, M., K. Morimoto and S. Maruyama, 2004. "Effect of work-related factor and workfamily conflict depression among Japanese working women living with young children". Environmental Health and Preventive Medicine, 9, 220-227.

Shaffer, M. A., D. A. Harrison, K. M. Gilley and D. M. Luk, 2001. "Struggling for balance amid turbulence on international assignments: work-family conflict, support and commitment". Journal of Management, 27, 99-121.

Spector, P. E., T. D. Allen, S. Y. Poelmans, L. M. Lapierre, C. L. Cooper and M. O'Driscoll, 2007. "Cross-national differences in relationship of work demand, job satisfaction, and turnover intentions with work-family conflict". Personnel Psychology, 60, 805-835.

Subiyanto, P., 2004. Avalilable at http://www. balipost.co.id/balipost cetak/2004/8/1/kel1_html.

Struch, N., S. H. Schwartz and W. A. van der Klor, 2002. "Meanings of basic values for women and men: a cross-cultural analysis". Personality and Social Psychology Bulletin, 28, 16-28.

Sumatika, W., 2006. Available at http://www. balipost.co.id/balipostcetak/2006/8/18/f1.ht $m$.

Thompson, L. and A. J. Walker, 1989. "Gender in families: Women in marriage, work, and parenthood". Journal of Marriage and the Family, 51, 841-871.

Wang, C. Y., M. H. Chen, B. Hyde and L. Hsieh, 2010. 'Chinese employees' work value and turnover intentions in multinational companies: the mediating effect of pay satisfaction". Social Behaviour and Personality, 38, 871-894.

Wang, P., J. L. Lawler, F. O. Walumbwa and K. Shi, 2004. "Work-family conflict and job withdrawal intentions: the moderating effect of cultural differences". International Journal of Stress Management, 11, 392-412.

Wood, W. and A. H. Eagly, 2002. "A cross-cultural analysis of the behavior of women and men: implications for the origins of sex differences. Psychological Bulletin, 128, 699727.

Yang, N., C. C. Chen, J. Choi and Y. Zou, 2000. "Source of work-family conflict: A SinoU.S Comparison of effects of work-family demands". Academy of Management Journal, 43, 113-123. 